\title{
Marine protected area strategies: issues, divergences and the search for middle ground
}

\author{
Peter JS Jones ${ }^{1}$
}

This is the author's version of the published paper, which is freely available for download. The journal paper is subject to the publisher's copyright, but this version is exactly the same. It should be cited as:-

Jones, P.J.S (2002) Marine protected area strategies: issues, divergences and the search for middle ground. Reviews in Fish Biology and Fisheries 11(3), 197-216. doi:10.1023/A:1020327007975

Key words: harvest refugia, stakeholder participation, post-normal science

\footnotetext{
${ }^{1}$ Dept of Geography, University College London, Pearson Building, Gower Street, London WC1E 6BT, UK, P.J.Jones@ucl.ac.uk, tel. +44 (0)20 7679 0528, www.geog.ucl.ac.uk/ pjones
} 
Abstract

\section{Introduction}

Attributes of the marine environment

Introduction

Ecological differences

Management differences

\section{MPA objectives}

The importance of objectives

Review of ten objectives

Value conflicts

Limitations of scale: case study of coral reefs

\section{International MPA review}

Biogeographical priorities

Management effectiveness

\section{MPA selection/design}

Structure and process-oriented perspectives

Role of Science

Multiple-use or set aside?

\section{Different approaches to MPA management}

\section{Conclusions}

\section{Acknowledgements}

\section{References}




\begin{abstract}
There has been a dramatic increase in recent years in the number of papers, reports, etc., which have been published concerning Marine Protected Areas (MPAs). This overview of the objectives, selection, design and management of MPAs aims to provide a basis for discussion regarding possible ways forward by identifying emerging issues, convergences and divergences. Whilst the attributes of the marine environment may limit the effectiveness of site-specific initiatives such as MPAs, it is argued that it would be defeatist in the extreme to abandon MPAs in the face of these limitations. Ten key objectives for MPAs are discussed, including that of harvest refugia, and it is argued that whilst these objectives may be justifiable from a preservationist perspective, they may be objected to from a resource exploitation perspective. MPAs generate both internal (between uses) and basic (between use and conservation) conflicts, and it is argued that these conflicts may be exacerbated when scientific arguments for MPAs are motivated by preservationist concerns. It is reported that a minority of MPAs are achieving their management objectives, and that for the majority insufficient information was available for such effectiveness evaluations. Structure and process-oriented perspectives on marine conservation are discussed. It is argued that there are two divergent stances concerning optimal MPA management approaches: top-down, characterized as being government-led and science-based, with a greater emphasis on set-aside; and bottom-up, characterized as being community-based and science-guided, with a greater emphasis on multipleuse. Given the divergent values of different stakeholders, the high degree of scientific uncertainty, and the high marine resource management decision stakes, it is concluded that a key challenge is to adopt a "middle-ground" approach which combines top-down and bottom-up approaches, and which is consistent with the post-normal scientific approach.
\end{abstract}




\section{Introduction}

This paper is an overview of issues concerning the objectives, selection, design and management of Marine Protected Areas (MPAs). The rationale for such an overview is that there has been a dramatic increase in recent years in the number of papers, reports, etc., which have been published concerning MPAs. This overview aims to provide a basis for discussions regarding possible ways forward by identifying emerging issues, convergences and divergences.

By way of background, this overview explores the development of MPA policy, the progress of MPA designations under international law and the attributes of the marine environment which influence the effectiveness of MPAs. The validity of ten general MPA objectives will then be assessed and the underlying value conflicts discussed. The extent to which these objectives can be achieved by MPAs considering the scale and connectivity of the marine environment will then be discussed with particular reference to coral reefs. The biogeographical representativity and management effectiveness of MPAs will then be assessed, drawing on a recent international review.

Against this background, emerging divergences of opinion about the best approaches to selecting, designing and managing MPAs will be discussed, particularly between those that argue for a top-down approach, based primarily on strategic scientific priorities, and those that argue for a bottom-up approach, based primarily on socio-economic priorities. The benefits and challenges of adopting a "middle ground" approach, which combines top-down and bottom-up approaches, are then discussed.

\section{The IUCN defines an MPA as:-}

"Any area of littoral or subtidal terrain, together with its overlying water and associated flora, fauna, historical and cultural features, which has been reserved by law or other effective means to protect part or all of the enclosed environment" (Kelleher and Kenchington, 1992).

The term "MPAs" includes intertidal reserves and areas focused on the protection of shipwrecks, archaeological remains, etc., some arguing that the term is so broad and vague that it has little value (Ballantine, 1999), and that its generality may obscure marine nature conservation objectives (Jones, 1994). A plethora of terms are used to describe such areas, depending upon the policy framework within which they are designated, the principal objectives, and the level of protection which is afforded to achieve these objectives. Ballantine (1999) argues that the term "marine reserve" should be used generally in order to rationalize site-based approaches to marine conservation, and that sites designated as such should always be strictly protected against extractive activities and disturbance. However, for the purposes of this paper the general term MPA shall be employed, but the focus will be on subtidal areas in coastal seas (generally within 12 nautical miles) for which the main objectives are related to nature conservation, and no particular degree of protection will be implied by the use of this term.

The world's first official MPA which included a substantial subtidal area was established at Glacier Bay, Alaska in 1925, incorporating coastal waters of importance to whale and seal populations. Ten years later, the first primarily subtidal MPA was established at Fort Jefferson, Florida, covering the Dry Tortugas system of coral reefs. However, Ray (1999) argued that the first "self-conscious" MPA, i.e., based on first-hand appreciation of marine life through the advent of snorkelling and SCUBA, was not established until 1959: Exuma Cays Land-and-Sea Park. It was another sixteen years before the first international meeting was held to review progress with MPAs and develop approaches for selecting, promoting and managing such sites (IUCN, 1976). The designation of MPAs has similarly proceeded in a relatively slow manner, with only 125 being recognized by 1974 (Bjorklund, 1974) and 1,306 by 1994 (Kelleher et al., 1995). Considering that around 37,000 terrestrial protected areas were then listed by the IUCN, it is clear that progress with marine site protection has lagged behind terrestrial initiatives.

Guidance to support the selection, designation and management of MPAs has also been relatively slow in its development. The IUCN first published guidelines for establishing MPAs in 1984, aimed primarily at planners and managers of MPAs for coral reefs and mangroves in developing countries (Salm and Clark, 1984), and these have recently been updated (Salm et al., 2000). More widely applicable guidelines for MPAs were published by the IUCN in 1992 (Kelleher and Kenchington, 1992) and these have been updated to reflect recent developments and experiences (Kelleher, 1999). In addition to such IUCN guidance, experiences around the world concerning the different principles and techniques for managing MPAs have been compiled (Gubbay, 1995), and two guides focused mainly on the use of MPAs in fisheries management have been published (Roberts and Hawkins, 2000; NRC, 2001). 


\section{Attributes of the marine environment}

\section{Introduction}

The designation of nature reserves is an approach to conservation that has primarily been developed and applied in the terrestrial environment. When considering the relative lack of progress with the designation of MPAs, it must be recognized that there are a number of attributes of inshore marine environments which, to a degree, limit the potential effectiveness of such site specific approaches. The implications of these differences for marine conservation strategies have been reviewed by a number of authors, e.g., Agardy (1997), Kenchington (1990), NRC (2001), Norse (1993) and Ray (1976). There are a number of ecological and management differences between inshore marine and terrestrial environments which are particularly important in this respect.

\section{Ecological differences}

\section{$\underline{\text { Scale }}$}

Marine ecosystems tend to exhibit wide spatial scales and have relatively indistinct boundaries, based on physiographic features such as sea temperature, salinity or current fronts, tectonic features, etc. Terrestrial ecosystems, on the other hand, tend to exhibit narrower spatial scales and are bound by relatively distinct physiographic boundaries, e.g., landscape features and geological changes. However, Ray (1996) reviews arguments against this view of the sea as a homogenous domain and argues that the complex trophic patchwork or mosaic structure of marine systems should be recognized. Though these arguments are valid, it must be recognized that subtidal environments are generally relatively homogenous and wide-scale, compared to the more heterogeneous terrestrial environments. This will influence the potential effectiveness of MPAs which are necessarily characterized by being site-scale specific. MPAs are generally considered to be particularly appropriate for site-dependent species with limited dispersal (Boersma and Parrish, 1999).

Norse (1993) reviews different types of critical marine areas to which site-specific protection is particularly appropriate, such as areas of: high diversity; endemism and productivity; spawning and nursery grounds; migration stopover points and bottlenecks; and areas of importance to particularly vulnerable species. Such critical areas often become the basis on which MPAs are selected. Their importance serves to illustrate that, despite the scale of marine ecosystems, site-specific measures often do have a role in conservation efforts, though arguably not in as many circumstances or to the same degree of effectiveness as for terrestrial ecosystems.

\section{Connectivity}

Arguments concerning scale are closely related to these for connectivity, in that areas which are spatially separated are more likely to be functionally connected in marine ecosystems than in terrestrial ecosystems. This clearly influences the selection and design of MPAs and their potential effectiveness in achieving certain objectives. Ray and McCormick-Ray (1994) argue that the general effectiveness of MPAs is critically dependent upon whether their design takes account of the functional connectivity over wide spatial scales between different parts of the ecosystem mosaic, whilst Roberts (1997; 1998) stresses the importance of recognising the connectivity between sources and sinks of recruits in designing MPAs for fisheries management.

\section{Variability}

Biological communities in inshore seas tend to exhibit particular variability or discontinuities due to a combination of biotic, abiotic and anthropogenic factors, the interactions between which are increased by the connectivity of the marine environment (Ray, 1996). Inshore marine ecosystems can be particularly complex due to the interactions between a diversity of communities in a wide range of niches, which often have non-linear population dynamics. Therefore, populations may rise and fall in a relatively unpredictable and non-attributable manner due to complex interactions between the ecological dynamics of different communities. Such variations also occur in response to variations in the physical environment, such as changes in currents, terrestrial run-off and coastal geomorphology.

Human activities often also affect inshore communities, and the connectivity of the marine environment means that such activities may occur a considerable distance from the MPA, but can still have a significant impact on the communities in question. For example, overfishing off the coast of Alaska was one of the principal factors which led to the collapse of populations of Steller sea lions and harbour seals, which were an important food source for killer whales, which have in turn been forced to seek alternative prey, including sea otters in the shallow seas around the Aleutian Islands. The resulting decline in sea otters has set off a cascade of effects: populations of sea urchins, on which sea otters normally prey, have exploded, leading to the overgrazing and 
collapse of kelp beds which are at the base of the inshore marine food web and provide an important habitat for many marine species (Estes et al., 1998)

An important consequence of such linkages is that management situations are often very complex through interactions between the impacts of human activities and the dynamics of a little known system (Kenchington, 1990). For example, outbreaks of the crown-of-thorns starfish (Acanthaster planci) can devastate coral reefs (Sapp, 1999), and there is evidence that the frequency and intensity of outbreaks has increased, exceeding the capability of corals to recover (Seymour and Bradbury, 1999). However, there is uncertainty as to the significance of anthropogenic impacts in perturbing these dynamics and exacerbating the impacts of such outbreaks by increasing their degree, extent and persistence, and as to which anthropogenic impacts might be particularly significant (Cameron et al., 1991; Kenchington and Kelleher, 1992). Outbreaks may be caused by increased crown-of-thorns starfish recruitment due to reductions in the populations of species that prey on larvae and juveniles as a result of commercial and recreational fishing (Ormond et al., 1990), or due to increased production as a result of increases in the terrestrial runoff of nutrients (Birkeland, 1982). This case illustrates how it can be very difficult to distinguish between natural and anthropogenic variations in inshore marine ecosystems and to link observed variations with specific anthropogenic impacts. Similarly, Dayton et al. (1998) discuss difficulties in establishing a natural benchmark against which changes can be evaluated, and in discerning natural from anthropogenic changes.

\section{Management differences}

\section{Naturalness}

Marine ecosystems are generally natural in management terms, in that they are rarely the result of positive intervention. By contrast, some terrestrial habitats considered to be of high conservation value, e.g., moors, lowland heaths and meadows, are semi-natural in that positive intervention through the maintenance of certain human activities is required to preserve them in their modified state (Sutherland and Hill, 1995). Marine ecosystems are, to varying degrees, subject to negative interventions through anthropogenic impacts that result from a range of activities e.g., fishing. This leads to significantly modified ecosystems (Norse, 1993), and the majority of the world's coastal seas have been affected (Jackson et al., 2001; Vitousek et al., 1997). However, it is rarely argued that such activities should continue in certain marine areas because the impacted habitats are considered, as a result, to have developed a conservation interest. The general approach to the management of MPAs is therefore one of non-intervention in comparison to the active management approach to conservation which is often practised on land (Laffoley and Bines, 2000). MPA management essentially involves the minimisation of negative interventions, through the restriction of certain activities in certain areas, in order to maintain relatively natural ecosystems, rather than the promotion of positive interventions, through the selective continuation of certain activities, in order to maintain semi-natural habitats.

\section{Limited scientific knowledge base}

One reason that the potential of MPAs as a management tool has yet to be realized, is that the science underlying effective MPA development and management is poorly understood (Mascia, 2001). Our understanding of the structure and function of marine ecosystems is poor compared to that of terrestrial systems, due to logistical problems of observing and studying such environments and the related high costs, their complex and dynamic nature, and the fact that humans are a predominantly terrestrial species. The management problems related to variability are compounded by a lack of understanding of the abiotic and biotic dynamics and processes that shape marine communities (Kenchington, 1990). This has a number of fundamental implications for the selection, design, management, and evaluation of MPAs, related to factors such as a lack of long-term baseline monitoring studies, a lack of knowledge about trophic relationships over different spatial and temporal scales, and difficulties in gaining scientific evidence to support claims concerning sustainable exploitation levels and cause-effect relationships. However, Ludwig et al. (1993) argued that scientific uncertainty is not necessarily an obstacle to conservation initiatives, and that actions should be taken on an iterative, adaptive basis which recognizes scientific uncertainty, rather than delaying actions in the quest for scientific certainty.

\section{The multiple use of coastal seas}

On land, different activities tend to occur in dedicated areas, interactions between which can be managed with relative ease, conflicts generally being based on competition between different users for a given area, e.g., agriculture and conservation. Disputes can often be resolved at a local or regional level. However, inshore seas are characterized by a growing intensity and diversity of multiple uses within the same area, with different societal sectors perceiving such ecosystems to be valuable in different ways, often leading to conflicts. Even 
where activities are spatially separated, the connectivity of marine ecosystems increases the scale of related impacts, and thereby the geographical distance over which negative interactions may potentially occur, leading to "down-stream impacts." This in turn means that MPA management must often address a relatively wide range of conflicts at a relatively wide spatial scale. Furthermore, the principle of the "freedom of the seas" is widely recognized, leading to a general expectation amongst many stakeholders of relatively open access and a resistance to proposals to implement access restrictions.

The manner in which these multiple uses are managed is also significant, in that there is rarely an overarching management framework. Management authority is often restricted to a given agency's statutory remit over a specific sectoral activity, which hinders integration initiatives. Jurisdictional frameworks are also often complicated, with significant gaps and overlaps in their boundaries, leading to the potential for "turf battles" between different sectoral agencies. Furthermore, most marine resources are not subject to property rights or are subject to common property rights, making it difficult to safeguard them through exclusive ownership and other market mechanisms, and rendering them prone to unregulated competitive over-exploitation (Hardin, 1968).

\section{The alien nature of marine ecosystems}

To the majority of observers of coastal seas, most of the adverse effects of disturbance are not apparent. Even if people are aware of the adverse effects of certain uses, our lack of familiarity and empathy with most marine life, and its general lack of intrinsic appeal, mean that the reaction is more likely to be one of indifference. Also, marine populations do not follow familiar seasonal patterns and the sea itself is also often seen as an adversary. However, it is important to remember that such alienation and perceptual hurdles (Kenchington, 1990) can positively affect human perception of the seas, many people having a particular interest in marine life because it is unusual, mysterious and unpredictable.

It could be argued that society's relation to the sea is largely defined in terms of the resources it provides, particularly as a place to harvest fish, dilute and disperse liquid wastes, and undertake marine navigation. Land, on the other hand, is conceived as a tangible entity in itself, the uses of which can be spatially divided, including the set-aside of areas for nature conservation (Cole-King, 1995).

\section{MPA objectives}

\section{The importance of objectives}

Clearly, the ecological and management-related attributes of marine environments will significantly influence the potential effectiveness of MPA initiatives. When assessing the degree to which MPAs can be effective against the background of these attributes, it is important that the detailed objectives of specific initiatives are formulated, and that consensus on their validity is reached amongst relevant stakeholders. Failure to do this is likely to undermine arguments for establishing MPAs and exacerbate conflicts during the formulation and implementation of management policies (Jones, 1994). Furthermore, detailed objectives are an essential basis for MPA selection (Vanderklift and Ward, 2000) and effectiveness evaluation. Ten general objectives for inshore MPAs, which are primarily focused on nature conservation, can be identified:

- $\quad$ Protect rare and vulnerable habitats and species

- Conserve a representative set of habitat types

- Maintain and restore ecological functions

- Promote research and education

- Harvest refugia

- Control tourism and recreation

- Promote integrated coastal management

- Maintain aesthetic values

- Maintain traditional uses

- Cultural symbolic value of set-aside areas

Review of ten objectives

$\underline{\text { Protect rare and vulnerable habitats and species }}$

The risk of species extinction in marine ecosystems has not generally been considered as being significant, on the basis that most species are widespread as a result of the wide scale and connectivity of such ecosystems. 
Therefore, narrow endemism amongst marine species is relatively low, making them less vulnerable to extinction than terrestrial species. Reviews by Roberts and Hawkins (1999) and Powles et al. (2000) indicate that only five invertebrates, all molluscs, are recorded as having become extinct. However, it is also argued that many other species are "missing in action" i.e., were once recorded but have not been recorded recently, or are known to be on the brink of extinction, and that many species may have become extinct without ever being recorded (Culotta, 1994; Malakoff, 1997; Norse, 1993; Roberts and Hawkins, 1999). Culotta (1994) concluded that marine and terrestrial extinction rates should not be compared on the same basis. As the scale and connectivity of marine ecosystems means that if extinctions or depletions are occurring, the causative problem may be on a very large scale and could potentially have wide implications. In view of the unprecedented degree and extent of pressures on inshore seas, and increasing awareness of the limited range of many species and of aspects of their life cycles that render them vulnerable to extinction, Malakoff (1997) argued against the myth that marine species are "extinction proof."

Similarly, Roberts and Hawkins (1999) and Powles et al. (2000) identified a number of factors that render certain marine species particularly vulnerable to extirpation and extinction including: small geographic range: dependency on rather limited, vulnerable and/or patchily distributed habitats; low fecundity; long and unpredictable intervals between recruitment; low dispersal ability; and strong Allee effects. Given increasing knowledge of the number of populations which exhibit such characteristics, and the widespread impacts of fishing, Roberts and Hawkins (1999) concluded that documented extinctions may only be the visible crest of a marine extinction wave that has been underway since the $19^{\text {th }}$ century and is now gathering force.

Such fears are validated by growing concern over commercial fish stocks which are now considered at risk of extinction. Musick et al. (2000), note that the American Fisheries Society identified 68 marine fish species that they believe are at risk of extinction, whilst Malakoff (1997) notes that the IUCN added 118 marine fish species to its 1996 Red List of animals threatened with extinction. However, there has been controversy over the applicability of the IUCN's criteria for defining different categories of risk for marine species, particularly those based on the rate of decline in abundance, as some fisheries biologists argue that this may not be appropriate to stocks where declines may be due to natural variability (Powles et al., 2000). There are also concerns that some criteria may not be precautionary enough for marine species (Powles et al., 2000), and it has been argued that increases in the population-decline thresholds used to assign marine fish species to at-risk categories would be inconsistent with the precautionary approach (Hutchings, 2001). The IUCN's recent review of the existing criteria did not lead to the development of criteria specifically for marine species (IUCN, 2000).

Where marine species are being depleted and becoming rare, MPAs can help protect them against localized impacts, though the protection afforded is clearly restricted by the geographical extent and distribution of the MPAs. They do, however, have a particularly important role in protecting marine habitats which are critical to certain species during certain stages of the life cycles. They can also be important in protecting peripheral populations which are nationally rare because their distribution range is restricted to a small proportion of a nation's seas. Such peripheral populations may well be globally common, but Malakoff (1997) stressed that apparently widely distributed species may be revealed, by genetic studies, to consist of "concealed sibling species" that can have narrower ranges and therefore be more vulnerable to extinction. Roberts and Hawkins (1999), argued that losses of local populations are clearly indicative that a species might eventually disappear altogether. It is therefore argued that marine species are potentially more vulnerable to extinction than has traditionally been considered, and that MPAs have the potential to be an important tool in reducing the risk of such extinctions.

\section{Conserve a representative set of habitat types}

The conservation of a representative set of habitats is the classic structure-oriented approach to conservation. Efforts are focused on preserving examples of all major habitat types within a biogeographic region, based on a hierarchical classification scheme, as a means of ensuring the protection of species biodiversity and a range of habitats. By preserving representative ecosystems, MPAs are likely to ensure the conservation of species and genetic diversity (NRC, 2001). One of the recommendations of the IV World Congress on National Parks and Protected Areas was that a global system of MPAs representing all major biogeographic types and ecosystems should be established (IUCN, 1993). Accordingly, one of the key themes of the recent international review of MPAs (Kelleher et al., 1995) discussed below was an assessment of the degree to which existing designations represent the major biogeographic types in each marine region. Efforts relating to this objective are often focused on areas which are rich, in terms of the number of different habitats and species they support, as a means of maximising representation within a given area. 


\section{Maintain and restore ecological functions}

There is growing awareness of the high value of coastal seas in terms of the ecosystem services they provide (Costanza et al., 1997), and this is leading to calls for a more process-oriented approach to marine conservation, in keeping with the land ethic (Callicot, 1991). There is also growing awareness of the degree and extent of disturbances to coastal marine ecosystems, particularly those disturbances resulting from fishing (Jackson et al., 2001). However, there is a societal perception problem in this respect, in that most people do not appreciate the importance of marine ecosystem goods and services (Peterson and Lubchenco, 1997). Therefore, marine ecosystem conservation is generally a low societal priority (Jones, 1999a).

Agardy (1997) argues that most impacts occur in coastal seas where the majority of areas critical to ecosystem functioning and productivity are found, and that the protection of such critical marine areas is of paramount importance. Jackson et al. (2001) and Pitcher (2001) go further in calling for initiatives to restore coastal marine ecosystems back to their original states as revealed by palaeoecological, archaeological and historical records, rather than using more recent "shifting baselines" as restoration targets. Jackson et al. (2001) argue that such ambitious measures are necessary to restore ecosystem resilience to other anthropogenic impacts, such as eutrophication and global warming.

\section{Promote research and education}

It is clear that scientific investigations need benchmark areas that are as unaffected as possible by human activities such as fishing, recreation and waste disposal, as the effects of these could obscure the natural processes under investigation. Such benchmark areas can be valuable for comparatively assessing the ecological impacts of harvesting in exploited areas, for studying natural fisheries dynamics and ecosystem functioning, and for monitoring wide scale natural and anthropogenic changes in the absence of localised anthropogenic impacts (Murray et al., 1999; NRC, 2001). MPAs are also a focus for educational activities and initiatives to raise public awareness in order to promote marine conservation in general, and, more specifically, for promoting support for the effective management of MPAs (Kaza, 1995; Alder, 1996a).

\section{Harvest refugia}

Areas which are partially closed, i.e., during certain times of the year, and/or are restricted to certain fishing techniques, are becoming increasingly recognized as a means of protecting areas critical to certain fisheries and as such are an important and relatively accepted aspect of fisheries conservation policy. There are growing calls to combine fisheries and nature conservation objectives through the designation of MPAs which incorporate notake zones, also referred to as fisheries marine reserves (FMRs) (NRC, 2001). Such calls are based on increasing concerns about the sustainability of fisheries and the wide-scale impacts of fishing on marine ecosystems (Botsford at al., 1997; FAO, 2000; Jennings and Kaiser, 1998; Jackson et al., 2001), coupled with the many benefits that FMRs offer not only for achieving marine conservation objectives such as those discussed in this paper, but also for fisheries conservation. Used in combination with other fisheries conservation measures, FMRs can: (1) help replenish stocks, enhance recruitment and sustain catches by the spillover of adults and export of larvae into fished areas; (2) provide insurance and resilience in the face of stochastic ecological dynamics, uncertainty over fisheries modeling and assessments, and enforcement problems; (3) protect habitats critical at certain stages of fish stock life cycles; and (4) provide areas for the study of fisheries and wider marine ecology (Guenétte et al., 1998; NRC, 2001).

A number of modeling exercises which indicate that FMRs may yield such benefits have been reported (e.g., Guénette et al., 1998; Holland, 2000; Sumaila et al., 2000; NRC, 2001), particularly for populations with sedentary adults, (e.g., Hannesson, 1998; Hastings and Botsford, 1999; Nowlis and Roberts, 1999). However, the number of evaluations which indicate that such benefits have actually been achieved are limited (Guénette et al., 1998; Roberts et al., 2001; Sumaila et al., 2000), partly because the spatial and temporal heterogeneity of inshore marine ecosystems means that it is difficult to distinguish between reserve effects and habitat effects (Garcia-Charton and Perez-Ruzafa, 1999). Many reported evaluations have been for non-migratory fisheries, particularly on coral reefs, and only one such study reports overall catch-per-unit-effort increases after FMR creation (Roberts et al., 2001). The majority of evaluations are limited to indicating that fish sizes and numbers increase within FMRs (Halpern, in press) and around their boundaries, including limited anecdotal evidence that such increases have led to the support of fishermen who previously opposed closure, e.g., Ballantine (1989). The lack of data demonstrating the benefits of FMRs coupled with difficulties in undertaking such evaluations have led to calls for FMRs to be established on a precautionary basis (Lauck et al., 1998; Murray et al., 1999).

Overall, observations of discussion fora, such as the California Marine Protected Area Network (CMPAN), and news reports indicate that fishermen tend to object to proposed FMRs to achieve both fish stock and marine 
nature conservation objectives on the grounds that the benefits of such designations are unproved and that the motives for such proposals are based on preservationist rather than fisheries conservation concerns. Unfortunately, demonstrating the benefits of FMRs through rigorous evaluations is extremely problematic given that a sufficient number of comparable areas to provide for statistically adequate replication first have to be successfully closed to all fishing activities (Murray et al., 1999), often in the face of objections from fishermen. Furthermore, the connectivity and variability of inshore marine ecosystems means that it is difficult to confidently relate wider fisheries benefits to specific FMRs, particularly for migratory species. Nonetheless, in the face of the evident failure of current measures to conserve fisheries, it is likely that calls and efforts to raise community support for FMRs on a precautionary or adaptive trial basis will increase, as will efforts to rigorously demonstrate their fisheries and marine conservation benefits.

\section{Control tourism and recreation}

Tourism and recreation related activities and developments are recognized as one of the main pressures on coastal seas, and many MPAs have been designated in response to the impacts of divers on popular but vulnerable habitats such as coral reefs. One of the key concerns is that divers will damage the very attributes of the area that attracted them in the first place, thus endangering the sustainability of this economically important activity and undermining other uses (Davis and Tisdell, 1995; Kenchington, 1993). Since these interests are concentrated on specific "hot spots" from both a marine biodiversity and tourism perspective, such as coral reefs, site specific protective measures through MPAs are widely argued to be particularly appropriate.

\section{Promote integrated coastal zone management (ICZM)}

MPAs are often seen as a means of developing and demonstrating the overall benefits of management approaches which enable multiple uses to co-exist on a sustainable basis in areas which are subject to a diversity of pressures (Kenchington and Agardy, 1990). As such, MPAs can be a catalyst in that they are small-scale models of integrated marine resource management which should be practised on a much wider scale (Agardy, 1994). The Great Barrier Reef Marine Park (GBRMP) is widely regarded as "flagship" initiative in this respect (Kelleher and Kenchington, 1982; Kenchington and Agardy, 1990; Kenchington, 1990). Management approaches which provide for multiple-uses are particularly important in marine environments, as the provision of access and allowance of certain activities is widely perceived as a reasonable expectation, compared to terrestrial areas where exclusion and strict protection is a relatively familiar and accepted conservation approach. Critics argue, however, that the extremely small proportion of multiple-use MPAs which are set-aside undermines conservation objectives (Brailovskaya, 1998; Prideaux et al., 1998), as is discussed below in the discussion on "multiple-use or set-aside."

\section{Maintain aesthetic values}

Coastal seas are particularly important in this respect, due to their openness and naturalness, from both a seascape and a marine wildlife perspective. MPAs can serve to both preserve particularly important marine areas as a source of aesthetic values and to promote interest in marine wildlife and related tourism opportunities.

\section{Maintain traditional uses}

MPAs can provide for the continuation of small-scale traditional uses and exclusion of modern, marketeconomics driven exploitation as a means of maintaining both natural and cultural heritage values, particularly in developing countries (Alder 1996b). Silva and Desilvestre (1986) discussed this in terms of the protection of areas where seafood dependent indigenous cultures have maintained their coastal subsistence way of life. Such areas can also serve to maintain and demonstrate the value of subsistence cultural approaches to marine resource management (Johannes, 1978). To this end, the Convention on Biological Diversity (Article 10(c), UNCED, 1992) calls for measures to protect customary uses of biological resources that are sustainable. MPAs are recognized by many as being important for the maintenance of traditional uses. However, it has been argued that MPAs, pursued in the context of ICZM projects funded by development organisations, can subvert traditional resource management systems and promote market-economics driven exploitation by external interests (Nichols, 1999), thus actually undermining this objective.

There are also a number of papers which call the effectiveness of small-scale traditional approaches to fisheries management into question. Ray (1976) argued that it would be a great error to categorize traditional subsistence cultures as right and the industrialized peoples as wrong, i.e., it should not be assumed that traditional cultures have an ecological basis. Polunin (1984) argued that traditional approaches to fisheries management based on tenure were competitively driven by a desire for gain rather than cooperatively driven by a 
desire for restraint. Cooke et al. (2000) report that the effectiveness of customary management varied between different areas in Fiji. Some exhibited quite a high degree of management and others exhibited very little or effectively no management. Jackson et al.'s (2001) findings revealed that overfishing by indigenous populations began to fundamentally alter some coastal marine ecosystems many thousands of years before present, and they argued that these findings undermine the romantic notion of the supposedly superior ecological wisdom of nonWestern and precolonial societies. Even if it is accepted that some indigenous cultures are ecologically enlightened and can effectively manage fisheries, Ray (1976) argued that it must be recognized that traditional ways are subject to external influences and changing technology. This is particularly the case given the increasing influence of globalization, and this must be recognized when incorporating the maintenance of traditional activities into the objectives and management of MPAs. Such concerns about the effectiveness of traditional management approaches potentially undermine the validity of this objective.

\section{Promote the cultural symbolic value of MPAs as set-aside areas}

This objective is derived from the "moral conviction that it is right" to preserve natural areas and the species they support (Leopold, 1964), regardless of any scientific or resource management objectives. Indeed, Pearsall (1984) argued that the likelihood of market values actually accruing from any given species is very small, therefore, public support for species protection must be founded on ethical perceptions of which set-aside are symbolic. Set-aside areas have also been discussed as being the modern equivalent of pre-Christian sacred places in a society that has otherwise lost its links with the ecological community, though it is argued that there is a difference in the way that nature is regarded and the trade-offs that are permissible (UNEP, 1995). In a related sense, set-aside areas are also generally considered to be an important means of fulfilling the human race's stewardship duties on behalf of future generations, on behalf of plants and animals themselves, or on behalf of God, i.e., with dominion comes responsibilities.

\section{Value conflicts}

The objectives discussed above may appear to marine conservationists and scientists to be justifiable and achievable through the designation and management of MPAs. However, experiences from around the world have shown that MPA proposals are often contentious in that they generate conflicts. It is possible to identify two bases for such conflicts.

Internal conflicts occur between different user interests and emerge in MPAs when one sector feels that they are being discriminated against in favour of another. For instance, MPA proposals in Britain led to a number of internal conflicts between divers and fishermen, where proposed restrictions on shellfish collecting on one were felt to be unfairly favouring the other (Jones, 1999b), and there are often conflicts where fishermen using towedbottom gear operate in the same areas as those using fixed-bottom gear (Kaiser et al., 2000). As such, internal conflicts are based on competition for marine resources and may be revealed by proposed MPA restrictions.

Basic conflicts are based on more fundamental differences in ethical views, between those who primarily believe that certain marine areas should be preserved, in keeping with the cultural benefits of the objectives discussed above, and those who primarily believe that marine resources should be exploited, albeit, to a greater or lesser degree, on a sustainable basis. This difference is in turn underpinned by differences between the preservation ethic and the resource conservation ethic (Callicot, 1991). To many proponents of resource exploitation, MPA proposals are not acceptable in a marine area where they have exploitation interests, unless they can be convinced by the resource management benefits of the objectives discussed above. Such conviction requires not only a long-term view and commitment to sustainable exploitation, but also an element of faith in the management and scientific principles underlying these objectives. In the majority of cases, this conviction is not widely held, leading to the objections, opposition, litigation, and even sheer defiance that characterizes the history of many MPAs.

Internal conflicts are relatively amenable to resolution through consensus and compromise. Basic conflicts are extremely difficult to resolve as negotiated settlement is foreclosed, because consensus is philosophically intolerable (Miller and Kirk, 1992). It is argued that the internal and basic value conflicts underlying debates concerning MPAs need to be taken into account when formulating policies and designing MPAs, in order that the appropriate conflict management approaches can be adopted.

It is also important, in this respect, to consider the value bases of the objectives that are being recommended by scientists for MPAs. Whilst scientists may profess that the scientific bases of such objectives are value-free, in keeping with the positivist or normal scientific tradition, it is possible that the scientists in question are consciously or subconsciously motivated by preservationist concerns and cultural benefits. Where users of proposed or existing MPAs suspect that this is the case, the credibility of the arguments behind the scientific 
objectives will be seriously undermined, and the basic conflicts related to MPAs will be significantly exacerbated. An illustration of this issue was provided in a debate in 1999 on the California Marine Protected Area Network (CMPAN) email discussion list, in which fishermen accused the scientists who were putting forward arguments for FMRs of being on a purely moral mission. Whilst it is important that scientists engage in debates concerning MPAs, it is equally important that arguments based on personal ethical views are distinguished from those based on scientific evidence, and that the degree of uncertainty concerning the latter is made clear. Statements which are implicitly biased by a personal ethical stance, potentially exacerbate conflicts and confuse issues. This approach will allow scientists to engage in debates and depart from a purely positivist approach by making statements based explicitly on their own ethical judgements, as well as statements based explicitly on scientific evidence, in keeping with the post-normal scientific tradition (Ravetz, 1999; Naylor L., pers. comm.) which will, in turn, provide for a constructive role for science as discussed below.

\section{Limitations of scale: case study of coral reefs}

As discussed above, the scale and connectivity of marine ecosystems limits the effectiveness of MPAs in achieving their objectives. MPAs are limited in their spatial scale and cannot protect wide ranging planktonic and migratory species against impacts beyond the boundaries of the MPA. They are, however, particularly effective for closed species whose propagules do not disperse far from adults, and which are territorial or otherwise limited in range. Coral reefs are particularly appropriate in this respect, and in that they are of outstanding value in terms of their biodiversity, economic resource, ecosystem function and intrinsic appeal value. This outstanding value is reflected by the fact that $274(21 \%)$ of the 1,306 MPAs identified by Kelleher et al. (1995) cover coral reefs (though Spalding et al. (2001) subsequently listed over 660 coral reef MPAs) and that much of the MPA guidance is aimed mainly at coral reef MPAs, e.g., Salm et al. (2000), Mascia (2001). This is significant in that Davidson (1998) revealed that coral reefs only account for around $0.2 \%$ of the global ocean area, but around $33 \%$ of all marine fish species and $25 \%$ of the total number of marine macro-species are found on coral reefs. Therefore, their over-representation, in terms of numbers of MPAs, is arguably justified in terms of the proportion of marine biodiversity they support. Coral reef species also tend to be relatively restricted in their range and have more specialised habitat requirements, making them more vulnerable to extinction (Hawkins et al., 2000; Roberts and Hawkins, 1999)

The effectiveness of the 274 coral reef MPAs reported by Kelleher et al. (1995) in protecting against localised impacts related to pollution, fishing, tourism, sedimentation, etc., is debatable, given the large proportion of coral reefs "at risk" (Spalding et al., 2001). The possibility is emerging that coral reefs may also be significantly threatened by two wide-scale impacts related to climate change. Firstly, the impacts of coral bleaching as a result of raised seawater temperatures are increasing, often as a result of El Niño/Southern Oscillation (ENSO) events (Wilkinson et al., 1999; Reaser et al., 2000), the incidence and intensity of which could be increasing as a result of climate change (Timmermann et al., 1999). It is worth noting that such bleaching may represent an adaptive response that helps corals to survive future warming events (Baker, 2001), and that ENSO disruptions are also likely to have consequences for temperate marine communities (Sanford, 1999; Dayton et al., 1998, 1999). Secondly, increased atmospheric $\mathrm{CO}_{2}$ concentrations could lead to a decline in coral reef-building capacity by decreasing the aragonite saturation state of seawater and thus inhibiting calcification (Gattuso et al., 1998; Kleypas et al., 1999). This could weaken coral reef skeletons, increasing vulnerability to erosion through storms which might increase in intensity/frequency with climate change, and reduce extension rates, reducing the ability of reefs to adapt to sea level rise.

Clearly MPA status will not protect coral reefs against such extreme wide-scale impacts. However, protection against localised impacts through effective MPA management could reduce the vulnerability of coral reefs to wide-scale impacts and promote the potential for adaptation to and recovery from such impacts (Salm et al., 2001). Similarly, the study of the effects of wide-scale impacts, which would be supported through MPA status, might raise awareness of the marine impacts of climate change and add to the pressures to address this global issue, in keeping with the objective of promoting research and education. This case study serves to illustrate that whilst MPAs are limited to a degree in their potential effectiveness in achieving their objectives due to their limitations of scale, this does not undermine their role in marine conservation and it would be defeatist in the extreme to abandon MPAs due to such limitations. 


\section{International MPA review}

\section{Biogeographical priorities}

Kelleher et al. (1995) assessed the number, representativity and effectiveness of MPAs within 18 biogeographic regions. Table 1 sets out the basic findings of this review in terms of the distribution of MPAs amongst the 18 biogeographic regions.

This analysis, coupled with specific information on the biogeographic representation of the MPAs within each region/zone, was used as the basis for specific recommendations concerning regional (Table 1) and national priorities for proposed new MPAs and for existing MPAs that require management support. This was with a view to achieving the objective, discussed above, that a global system of MPAs representing all major biogeographic types and ecosystems should be established.

\section{Management effectiveness}

As the above priorities for MPAs which require increased management support imply, a key objective of the review was to assess the extent to which MPAs around the world are achieving their management objectives (Table 2). It is debatable whether the proportion of MPAs, for which sufficient information was available (383 representing $29 \%$ of the total), which were found to have a high level of management (31\% of 383 MPAs) is representative of the great proportion of MPAs for which insufficient management information was available ( 923 representing $71 \%$ of the total). It is possible that a lack of management information is indicative of a poor management regime, in which case the total proportion of MPAs which have a high management effectiveness will be less than $31 \%$. A "worst case" interpretation of the above figures is that only $9 \%$ (117) of the total number of MPAs around the world $(1,306)$ could be classified as having high management effectiveness. Even if the MPAs for which sufficient management information was available are representative of the total number, the figures still indicate that $29 \%$ of MPAs are failing to meet their management objectives, which clearly indicates that there is great scope for the improvement of MPA management effectiveness. Kelleher et al. (1995) stressed that that there were variations between bioregions as to the reasons why MPAs were failing to meet their management objectives, but identify the following commonly recurring themes, many of which resonate with the issues discussed in this paper:

- Insufficient financial and technical resources, including a lack of trained staff, to develop and implement management plans.

- Lack of data for management decisions, including information on the impacts of resource use and on the status of biological resources.

- Lack of public support and unwillingness of users to follow management rules, often because users have not been involved in establishing such rules.

- Inadequate commitment to enforcing management.

- Unsustainable use of resources occurring within MPAs.

- Impacts from activities in land and sea areas outside the boundaries of MPAs, including pollution and overexploitation.

- Lack of clear organisational responsibilities for management and absence of coordination between agencies with responsibilities relevant to MPAs.

Such evaluations of the performance and effectiveness of MPAs are critically important. If an MPA is failing to achieve its objectives and this failure is not detected, a false sense of security can be imparted to managers and stakeholders. This mistaken security may jeopardize the future of not only the MPA, but also of regional management policies which are supported by the MPA (Murray et al., 1999). An important caveat when considering Kelleher et al.'s (1995) review is that it did not address the level of protection which was afforded by the various types of MPA designation, other than an assessment of whether the management objectives were generally being met. Therefore an MPA which had modest management objectives might be classified as generally meeting these, whilst an MPA which had ambitious management objectives, and thus more use restrictions, might be classified as not meeting these, despite the fact that the ambitious MPA may be achieving more for marine nature conservation. Future evaluations at a regional, national and international scale would benefit from an analysis of the different levels of protection afforded by the MPAs, rather than being confined to 
assessing simply whether the objectives, be they ambitious or otherwise, are being met. A three level categorisation of protection has been suggested (NRC, 2001):

MPA - an area designated to enhance the conservation of marine resources through an integrated plan that includes MPA-wide restrictions on certain activities, such as oil and gas extraction, and may also provide for higher levels of protection for delimited zones.

Fisheries marine reserve (FMR) - an area/zone that prohibits fishing activities for some or all species in keeping with the objectives of harvest refugia.

Ecological marine reserve (EMR) - an area/zone that protects all living resources through prohibitions on fishing and the removal or disturbance of any living or non-living marine resource, except as necessary for monitoring or research to evaluate reserve effectiveness.

The systematic use of such a classification for MPAs would enable more rigorous assessments of progress in designating a representative MPA network and, more importantly, of the potential and actual effectiveness of such a network.

\section{MPA Selection/Design}

\section{Structure and process-oriented perspectives}

There is a divergence between those who argue that MPAs should principally be selected in a structure-oriented manner on the basis of in terms of habitat types represented within a biogeographical region (e.g., Kelleher and Kenchington, 1992), and those who argue that they should principally be selected in a process-oriented manner on the basis of their criticalness in terms of ecosystem function (e.g., Ray and McCormick-Ray, 1994).

The structure-oriented view is consistent with the scientific objective of conserving a representative set of habitat types discussed above, and is characterized by the view that "it is better to create and manage successfully an MPA which may not be ideal in ecological terms but which nevertheless achieves the purposes for which it is established than it is to labour futilely and vainly to create the theoretically 'ideal' MPA" (Kelleher and Kenchington, 1992). Accordingly, the bottom-up approach is recommended in that it is argued that local people should be involved in MPA selection from the earliest possible stage by providing a scientifically derived list of potential MPAs for them to choose from, in order to overcome the potential for community opposition (Kelleher and Kenchington, 1992; Vanderklift and Ward, 2000). It is further argued that areas which are directly important for commercially or recreationally significant species should be included, as such resources are important to local economic interests. It is, therefore, not possible to divorce the questions of resource use and conservation (Kelleher and Recchia, 1998). An important aspect of this view is that there will often be a choice of potential MPAs when the structure-oriented approach is adopted. There is more scope for taking account of socio-economic factors and for compromise, when local people select MPAs from a provisional, scientifically derived list.

The process-oriented view is consistent with the objective of "maintaining and restoring ecological functions", as discussed above, and is characterized by the view that "unfortunately, there is an expedient tendency to speak to the lowest common denominator in proposing MPAs and their management, resulting from consensus-based participatory processes. This is self-defeating in the end-perhaps sooner rather than later" (Ray and McCormick-Ray, 1994). Accordingly, the top-down approach is recommended in that it is argued that MPA selection should essentially be based on scientific expertise in identifying ecologically critical areas and that community efforts should be focused on enhancing local people's acceptance of the scientifically prioritized sites. This view is strongly advocated by Agardy (1994) who argued that the protection of functionally important areas should be central to marine conservation, rather than the protection of species biodiversity "hotspots". Ray (1999) expressed the hope that such a process-oriented approach need not represent a "top-down, authoritarian regime", but goes on to argue that whilst social science must play a fundamental role in conservation, there is no escaping the bottom line that ecological science and monitoring are the primary components for MPA selection and management.

Whilst the structure-oriented approach represents the dominant paradigm in modern conservation, and, indeed, was used as the basis for the MPA review (Kelleher et al., 1995) discussed above, it has also been argued that structure and process-oriented approaches should be combined in identifying core MPA areas 
(Brunckhorst and Bridgewater, 1994). Similarly, Ballantine (1999) argued for an approach which provides for both the representation within MPAs of all major habitat types within a biogeographical region and for a selfsustaining ecological network of MPAs which maintains essential processes. Accordingly, Ballantine (1999) argued that top-down and bottom-up approaches need to be combined: scientists should determine the relevant principles and explain the potential benefits of MPAs, but the precise location and delimitation should be left to local people and socio-political processes. This combined approach clearly falls short of the principally sciencebased and process-oriented approach recommended above, but it could be argued that, whilst the processoriented approach is theoretically optimal, in the absence of full scientific information on the structure and functioning of marine ecosystems, scientific priorities must be integrated with socio-economic priorities through a combined process and structure-oriented approach.

\section{Role of science}

As is discussed above, there is a relatively limited scientific knowledge base for marine ecosystems which limits the extent to which the selection/design of MPAs can be based on an empirical scientific framework. Some argue that a comprehensive, hierarchical ecosystem classification is required to ensure structural representativity and also provide for a process-oriented ecosystem approach (e.g., Zacharias et al., 1998). Similarly, it has been argued that severely compromising the design or implementation of MPAs because of non-biological issues, such as funding, local participation and political feasibility and commitment, will jeopardize the original conservation goals (Allison et al., 1998). In this respect Murray et al. (1999) noted that there is often a mismatch between operative timescales for ecological, socio-economic and political processes which can result in inaccurate expectations of the time-course for reserve outcomes to be realized. This clearly has implications when attempting to gain wider support for scientifically predicted ecological benefits of MPAs.

On the other hand, it has been argued that such scientific detail is not required and that science should be confined to determining the principles and benefits of MPAs at a conceptual level, with site-specific details being left to local and political interests (e.g., Ballantine, 1999). Kelleher and Recchia (1998) argued that MPAs should not be postponed because of incomplete biophysical information, but also argued that science should be employed in the design of specific sites and that there will usually be sufficient information to do this. Similarly, Agardy (2000) argued that the specific objectives of particular MPAs represent crucial information, and that this information is ultimately societal, not scientific, though it is stressed that science is important in the design of MPAs. As was previously discussed, the level of scientific detail concerning marine ecosystems is not sufficient to adopt a purely process-oriented and science-based approach, and it is necessary to proceed with MPA designations in the face of knowledge gaps and uncertainty (Roberts, 1998; 2000) rather than labouring "futilely and vainly to create the theoretically 'ideal' MPA" (Kelleher and Kenchington, 1992). Accordingly, Roberts (2000) noted that most FMRs have been located and delineated largely on the basis of opportunism and compromise, rather than science, and that evidence suggests that such reserves show clear benefits. He argues that it is more important to have a network of a larger number of better enforced opportunistic reserves than to strive for scientifically optimal reserves which are more likely to be fewer in number and poorly enforced.

Whilst there are broadly two schools of thought in this respect, it is also clear that there is "middle ground" in that not even the most ardent scientist would argue that MPA initiatives cannot go ahead until comprehensive scientific certainty has been achieved, whilst not even the most ardent socio-political proponent would argue that science has no role in selecting, designing and managing MPAs. Clearly, more scientific evidence for the benefits of MPAs will increase socio-political support for such approaches, but many scientists are agreed that existing scientific information justifies the application of FMRs as a central management tool (NCEAS, 2001). However, there clearly remains a divergence between those that argue for a principally scientific approach, on the basis that rigorous theoretical and empirical approaches should not be compromised by socio-political factors, and those that argue for a principally socio-politically acceptable approach, on the basis that this is, pragmatically, the only way forwards. It could therefore be argued that a key challenge is the determination of a constructive role for science in the selection, design and management of MPAs, accepting that this role lies somewhere between these divergent views.

\section{Multiple-use or set-aside?}

Many MPAs provide for a range of compatible activities on the basis that "in the sea the provision for reasonable use is usually a prime consideration" (Kelleher and Kenchington, 1992). This has led to the development of the multiple-use management approach which has been defined under the US National Marine Sanctuary Program as "contemporaneous utilization of an area or resource for a variety of compatible purposes to the primary purpose so as to provide more than one benefit" (Tarnas, 1988 after 15 CFR (1)(b), 1975). This approach is central to the objective discussed above of promoting ICZM. It is also supported on the basis that 
MPAs managed for multiple-use may gain more political support than areas set-aside for a single purpose (Tisdell and Broadus, 1989).

Discussions concerning whether multiple-use or set-aside MPAs should be the priority include issues similar to those concerning whether a single large or several small (SLOSS) reserves should be the priority. Kelleher and Recchia (1998) argued that where MPAs are concerned it is not a matter of either a single large or several small reserves as large multiple-use reserves should, and generally do, incorporate several small set-aside areas, and that such areas are more effective when they are managed within a compatible multiple-use framework. This combined approach is also consistent with the Man and Biosphere (MAB) model for biosphere reserves, as discussed above. However, there are growing concerns that such combined approaches go too far in providing for compatible uses at the expense of compromising primary conservation objectives.

Most crticizms are based on the extremely small proportion of marine areas which are actually set aside in multiple-use MPA programs. Only $0.3 \%$ of the US territorial sea has been designated under the National Marine Sanctuary Programme, of which a single area of only $285 \mathrm{~km}^{2}$ has been set-aside as a fisheries sanctuary in the Florida Keys National Marine Sanctuary, which represents approximately $0.002 \%$ of the total territorial sea area (Brailovskaya, 1998). This low proportion has led to arguments that attempting to balance set-aside and multiple-use management has weakened the US National Marine Sanctuary Program (Tarnas, 1988). Similarly, whilst the Great Barrier Reef Marine Park (GBRMP) is widely cited as an example of how successful multipleuse MPAs can be (e.g., Kelleher and Kenchington, 1982; Kenchington and Agardy, 1990), others have argued that the multiple-use approach provides mainly for exploitation rather than conservation, pointing out that only $4.6 \%$ of the GBRMP's area is set-aside (Prideaux et al., 1998). This contrasts with the views of proponents of MPAs as models of ICZM, as is discussed above in relation to the objective of promoting ICZM.

Against this background and the confusing plethora of terms employed for different zones, Ballantine (1999) defines marine reserves as complete no-take and undisturbed areas, all of which should be set-aside in their entirety, in keeping with the NRC's (2001) definition of ecological marine reserves discussed above. This would provide for marine reserves which are truly "reserved" through being set-aside to be distinguished from multiple-use MPAs which provide for exploitation. However, this approach would not be accepted by those who argue that compatible uses should be provided for through multiple-use MPAs which incorporate a small proportion of completely reserved zones, and there is thus a significant divergence between proponents of multiple-use and set-aside MPAs.

\section{Different approaches to MPA management}

For the purposes of this discussion, MPA management is taken to refer to the approaches which are employed to achieve the objectives for MPAs as discussed in this paper. This is ultimately achieved by promoting the appropriate behavior of users of the marine area in question, on the basis of which Fiske (1992); Kelleher (1999); Kelleher and Recchia (1998); and Milton (1991) have argued for approaches which recognize the values, concerns, knowledge and customary practices of stakeholders through providing for active participation in MPA management processes from the outset. Such processes also involve, to a greater or lesser degree, the development of appropriate policies and inter-agency relationships, and the application of various conflict management and consensus building approaches. It is extremely difficult, if not impossible, to produce a definitive and comprehensively applicable typology of different approaches to managing MPAs, as the management regime for each MPA is influenced by the ecological, cultural, political, socio-economic and institutional contexts in question. However, from the wide range of MPA cases that have been published, it is possible to identify two different stances concerning MPA management approaches (Figure 1).

Many of the divergences discussed, particularly those concerning the role of science, are consistent with these divergent stances. In order to combine strategic scientific and resource management objectives with the need to promote stakeholder cooperation, it is becoming increasingly recognized that it is necessary to combine top-down and bottom-up approaches by adopting collaborative management (co-management) approaches which provide for stakeholders and relevant government agencies to jointly manage MPAs (e.g., Kelleher, 1999; Kelleher and Recchia, 1998; Mascia, 2001).

For instance, 39 initially proposed marine Special Areas of Conservation (SACs) are currently being pursued in Great Britain, as they are throughout the European Union, in response to the European Commission's Habitats Directive. These areas were selected by government scientists but the implementation of the management schemes to conserve them must, under the domestic regulations which implement the Directive, rely primarily on the voluntary cooperation of stakeholders. Conservationists have argued that the domestic regulations for marine SACs are too weak, in that they do not provide the nature conservation agencies with executive cross-sectoral powers and that there is too much reliance on the voluntary cooperation of stakeholders to implement management schemes. There are other differing views on how such management schemes should 
be developed and implemented that are consistent with the divergent stances (illustrated in Table 1), but the fact remains that under the domestic legislation it will be necessary to develop the potential for stakeholder cooperation through adopting an appropriate bottom-up approach, in order to ensure compliance with a topdown strategic conservation initiative (Jones, 1999b). A number of different management models are evolving to meet this challenge. These models are appropriate to the context of each area, but it is argued that they need to be symmetrical in that they should provide for an appropriate balance between top-down and bottom-up approaches through a partnership or collaborative approach (Jones et al., 2001).

In general, in combining top-down and bottom-up approaches, it is argued that a related challenge is to manage the interactions between relatively "hard" top-down infrastructures and relatively "soft" bottom-up infrastructures (Figure 2). Failure to recognize these differences and to take account of them in the selection, design and management of MPAs is likely to exacerbate internal and basic conflicts and thus undermine the potential of the MPA to achieve its objectives.

\section{Conclusions}

The challenge discussed above, to combine top-down and bottom-up approaches and to compromise between taking an approach which is based primarily on strategic scientific or socio-economic priorities, is a major one. Strict proponents of either the top-down or the bottom-up approach will often argue that the two approaches are mutually exclusive. However, it is argued that experiences with MPAs are increasingly indicating that both approaches have their benefits, and that it is necessary to move forward from the either/or approach to one that recognizes that both approaches have a role. This is consistent with the wider concept of co-management, the importance of which in managing marine resources (Ellsworth et al., 1997; Nielsen and Vedsmand, 1999) and terrestrial protected areas (Agrawal and Gibson, 1999; Borrini-Feyerabend, 1996; Paulson, 1998; Sharpe, 1998; Tsing et al., 1999) is gaining wider and increasing recognition. This is particularly important for MPAs given: the diversity of stakeholders and their differing value priorities; the high degree of scientific uncertainty concerning marine ecosystems; and the high decision stakes should such ecosystems be perturbed.

As such, the "middle-ground" approach that is being argued for is consistent with the post-normal scientific approach (Ravetz, 1999; Naylor L., pers. comm.), outlined in the discussion above on "value conflicts", which others, such as Ballantine (1999) have also supported. Whilst some scientists may be hostile to such an approach, it is argued that it is becoming increasingly evident that if MPAs are to be designated more widely, managed more effectively, and evaluated more demonstrably, middle-ground approaches will be necessary. Where such approaches have been developed and successfully applied, it will also be important to share such experiences, through a network of parties with an interest in MPAs, and to assess their transferability, subject to adaptation where appropriate. This will enable MPAs to move forward from their present ad hoc approach, by providing an approach to selecting, designing, managing and evaluating MPAs which is systematic, though not in a purely scientific sense, and which is effective in achieving MPA objectives, including that of harvest refugia, through the promotion of stakeholder cooperation.

\section{Acknowledgements}

I am grateful to Dr Nicholas Polunin, University of Newcastle, and to the three anonymous reviewers for their useful comments on the initial manuscript.

\section{References}

Agardy T. (1994) Introduction. In Agardy T. (ed.) The science of conservation in the coastal zone: new insights on how to design, implement and monitor marine protected areas. A Marine Conservation and Development Report, IUCN, Gland, Switzerland, pp. 3-16.

Agardy T.S. (1997) Marine protected areas and ocean conservation. R.G. Landes Company, Texas.

Agardy T. (2000) Information needs for marine protected areas: scientific and societal. B. Mar. Sci. 66(3), 875888.

Agrawal A. and Gibson C.C. (1999) Enchantment and disenchantment: the role of community in natural resource conservation. World Dev. 27(4), 629-630. 
Alder J. (1996a) Costs and effectiveness of education and enforcement, Cairns Section of the Great Barrier Reef Marine Park. Environ. Manage. 20(4), 541-551.

Alder J. (1996b) Have tropical marine protected areas worked? An analysis of their success. Coast. Manag. 24(2), 97-114.

Allison G.W. Lubchenco J. and Carr M.H. (1998) Marine reserves are necessary but not sufficient for marine conservation. Ecol. Appl. 8(1) Supplement, S79-S92.

Baker A.C. (2001) Ecosystems: reef corals bleach to survive change. Nature 411, 765-766.

Ballantine W.J. (1989) Marine reserves: lessons from New Zealand. Progress in Underwater Science 13, 1-14.

Ballantine W.J. (1999) Marine reserves in New Zealand: the development of the concept and the principles. In Proceedings of International Workshop on Marine Conservation. Korean Ocean Research and Development Institute, Cheju Island, Korea, November 1999, pp. 3-38.

Birkeland C. (1982) Terrestrial runoff as a cause of outbreaks of Acanthaster planci. Mar. Biol. 69(2), 175-185.

Bjorklund M.I. (1974) Achievements in marine conservation: international marine parks. Environ. Conserv. 1(3), 205-223.

Boersma P.D. and Parrish J.K. (1999) Limiting abuse: marine protected areas, a limited solution. Ecol. Econ. 31(2), 287-304.

Borrini-Feyerabend G. (1996) Collaborative management of protected areas: tailoring the approach to the context. IUCN, Cambridge, UK.

Botsford L.W., Castilla J.C. and Peterson C.H. (1997) The management of fisheries and marine ecosystems. Science 277, 509-515.

Brailovskaya T. (1998) Obstacles to protecting marine biodiversity through marine wilderness preservation: examples from the New England region. Conserv. Biol. 12(6), 1236-1240.

Brunckhorst D.J. and Bridgewater P.B (1994) A novel approach to identify and select core reserve areas, and to apply UNESCO Biosphere Reserve principles to the coastal marine realm. In Brunckhorst D.J. (ed.) Marine protected areas and Biosphere Reserves: towards a new paradigm. Proceedings of the 1st International Workshop on Marine and Coastal Protected Areas, Canberra, Australia, August 1994. Australian Nature Conservation Agency, Canberra, pp. 12-17.

Callicot J.B. (1991) Conservation ethics and fishery management. Fisheries 16(2), 22-28.

Cameron A.M., Endean R. and DeVantier L.M. (1991) Predation on massive corals: are devastating population outbreaks of Acanthaster planci novel events? Mar. Ecol. Prog. Ser. 75, 251-258.

Cole-King A. (1995) Marine protected areas in Britain: a conceptual problem? Ocean Coast. Manage. 27(1-2), 109-127.

Cooke A.J., Polunin N.V.C. and Moce K. (2000) Comparative assessment of stakeholder management in traditional Fijian fishing-grounds. Environ. Conserv. 27(3), 291-299.

Costanza R., d'Arge R. and van den Belt M. (1997) The value of the world's ecosystem services and natural capital. Nature, 387, 253-260.

Culotta E. (1994) Is marine biodiversity at risk? Science 141, 918-920.

Davidson O.G. (1998) This enchanted braid: coming to terms with nature on the coral reef. John Wiley, New York, p. 5. 
Davis D. and Tisdell C. (1995) Recreational scuba-diving and carrying capacity in marine protected areas. Ocean Coast. Manage. 26(1), 19-40.

Dayton P.K., Tegner M.J., Edwards P.B. and Riser K.L. (1998) Sliding baselines, ghosts, and reduced expectations in kelp forest communities. Ecol. Appl. 8(2), 309-322.

Dayton P.K., Tegner M.J., Edwards P.B. and Riser K.L. (1999) Temporal and spatial scales of kelp demography: the role of oceanographic climate. Ecol. Monogr. 69(2), 219-250.

De Fontaubert A.C., Downes D.R. and Agardy T.S. (1996) Biodiversity in the seas: implementing the Convention on Biological Diversity in marine and coastal habitats. IUCN, Gland, Switzerland.

Ellsworth J.P., Hildebrand L.P. and Glover A.E. (1997) Canada's Atlantic Coastal Action Program: a community-based approach to collective governance. Ocean Coast. Manage. 36(1-3), 121-142.

Estes J.A., Tinker M.T., Williams T.M. and Doak D.F. (1998) Killer whale predation on sea otters linking oceanic and nearshore ecosystems. Science, 282, 473-476.

FAO (Food and Agriculture Organisation) (2000) The state of world fisheries and aquaculture 2000. United Nations, Rome.

Fiske S.J. (1992) Sociocultural aspects of establishing marine protected areas. Ocean Coast. Manage. 18, 25-46.

Garcia-Charton J.A. and Perez-Ruzafa A. (1999) Ecological heterogeneity and the evaluation of the effects of marine reserves. Fish. Res. 42(1-2), 1-20.

Gattuso J.-P., Frankignoulle M., Bourge I., Romaine S. and Buddemeier R.W. (1998) Effect of calcium carbonate saturation of seawater on coral calcification. Global Planet. Change 18(1-2), 37-46.

Gubbay S. (ed.) (1995) Marine protected areas: principles and techniques for management. Chapman and Hall, London.

Guénette S., Lauck T. and Clark C. (1998) Marine reserves: from Beverton and Holt to the present. Rev. Fish Biol. Fisher. 8(3), 251-272.

Halpern B. (in press) The impact of marine reserves: do reserves work and does reserve size matter? Ecol. Appl..

Hannesson R. (1998) Marine reserves: what would they accomplish? Marine Resource Economics 13(3), 159170.

Hardin D. (1968) The tragedy of the commons. Science, 162, 1243-1248.

Hastings A. and Botsford L.W. (1999) Equivalence in yield from marine reserves and traditional fisheries management. Science 284(5419), 1537-1538.

Hawkins J.P., Roberts C.M. and Clark V. (2000) The threatened status of restricted-range coral reef fish species. Animal Conservation 3(1), 81-88.

Holland D.S. (2000) A bioeconomic model of marine sanctuaries of Georges Bank. Can. J. Fish. Aquat. Sci. 57(6), 1307-1319.

Hutchings J.A. (2001) Conservation biology of marine fishes: perceptions and caveats regarding assignment of extinction risk. Can. J. Fish. Aquat. Sci. 58(1), 108-121.

IUCN (1976) Proceedings of an international conference on marine parks and reserves, 12-14 May, Tokyo, Japan. IUCN Publication New Series, No 37. 
IUCN (1993) Parks for life: report of the IVth World Congress on National Parks and Protected Areas. Caracas, Venezuela, February 1992. IUCN, Gland, Switzerland.

IUCN (2000) IUCN Red List categories: Version 3.1. Prepared by the IUCN Species Survival Commission. IUCN, Gland, Switzerland and Cambridge, UK.

Jackson J.B.C., Kirby M.X., Berger W.H., Bjorndal K.A., Botsford L.W., Bourque B.J., Bradbury R.H., Cooke R., Erlandson J., Estes J.A., Hughes T.P., Kidwell S., Lange C.B., Lenihan H.S., Pandolfi J.M., Peterson C.H., Steneck R.S., Tegner M.J. and Warner R.R. (2001) Historical overfishing and the recent collapse of coastal ecosystems. Science 293, 629-638.

Jennings S. and Kaiser M.J. (1998) The effects of fishing on marine ecosystems. Adv. Mar. Biol. 34, 201-352.

Johannes R.E. (1978) Traditional marine conservation in Oceania. Ann. Rev. Ecol. Syst. 9, 349-364.

Jones P.J.S. (1994) A review and analysis of the objectives of marine nature reserves. Ocean Coast. Manage. 23(3), 149-178.

Jones P.J.S. (1999a) Economic and sociocultural priorities for marine conservation. In Kaiser M.J. and de Groot S.J. (eds) Effects of fishing on non-target species and habitats: biological, conservation and socio-economic issues. Blackwell Science, Oxford, pp. 354-365.

Jones P.J.S. (1999b) Marine nature reserves in Britain: past lessons, current status and future issues. Mar. Policy 23(4-5), 375-396.

Jones P.J.S., Burgess J. and Bhattachary D. (2001) An evaluation of approaches for promoting relevant authority and stakeholder participation in European Marine Sites in the UK. UK Marine SACs Project, English Nature, Peterborough. Available from Internet URL http://www.ucl.ac.uk/ ucfwpej/icem.htm\#MSAC

Kaiser M.J., Spence F.E. and Hart P.J.B. (2000) Fishing-gear restrictions and conservation of benthic habitat complexity. Conserv. Biol. 14(5), 1512-1525.

Kaza S. (1995) Marine education and interpretation. In Gubbay (ed.) (1995), pp. 174-198.

Kelleher G. (1999) Guidelines for marine protected areas. IUCN, Gland, Switzerland and Cambridge, UK.

Kelleher G. and Kenchington R.A. (1982) Australia's Great Barrier Reef Marine Park: making development compatible with conservation. Ambio 11(5), 262-267.

Kelleher G. and Kenchington R.A. (1992) Guidelines for establishing marine protected areas. IUCN, Gland, Switzerland and Cambridge, UK.

Kelleher G. and Recchia C. (1998) Lessons from marine protected areas around the world. Parks 8(2), 1-4.

Kelleher G., Bleakley C. and Wells S. (1995) Priority areas for a global representative system of marine protected areas. Four Volume Report to the World Bank Environment Department, Washington DC.

Kenchington R.A. (1990) Managing marine environments. Taylor and Francis, New York, pp. 28-39.

Kenchington R.A. (1993) Tourism in coastal and marine environments- a recreational perspective. Ocean Coast. Manage. 19(1), 1-16.

Kenchington R.A. and Agardy T. (1990) Achieving marine conservation through biosphere reserve planning and management. Environ. Conserv. 17, 39-44.

Kenchington R.A. and Kelleher G. (1992) Crown-of-thorns starfish management conundrums. Coral Reefs 11, 53-56. 
Kleypas J.A., Buddemeier R.W., Archer D., Gattusso J.P., Langdon C. and Opdyke B.N. (1999) Geochemical consequences of increased atmospheric carbon dioxide on coral reefs. Science 284(5411), 118-120.

Laffoley D. d'A. and Bines T. (2000) Protection and management of nationally important marine habitats and species. Research Report 390, English Nature, Peterborough.

Lauck T., Clark C.W., Mangel M. and Munro G.R. (1998) Implementing the precautionary principle in fisheries management through marine reserves. Ecol. Appl., 8(1) Supplement, S72-S78.

Leopold A.S. (1964) Wilderness and culture. In Brower D. (ed.) Wildlands in our civilisation. Sierra Club, San Francisco, California, pp. 81-85. Quoted in Pearsall (1984).

Ludwig D., Hilborn R. and Walters C. (1993) Uncertainty, resource exploitation and conservation: lessons from history. Science 260, 17, 36.

Malakoff D. (1997) Extinction on the High Seas. Science 277, 486-488.

Mascia M.B. (2001) Designing effective coral reef marine protected areas. A synthesis report based on presentations at the $9^{\text {th }}$ International Coral Reef Symposium, Bali, Indonesia, October 2000. IUCN World Commission on Protected Areas-Marine, Gland, Switzerland.

Miller M.L. and Kirk J. (1992) Marine environmental ethics. Ocean Coast. Manage. 17 (3/4), 237-251.

Milton K. (1991) Gaining support for marine protected areas: a sociologists view. In The challenge of marine protected areas. Proceedings of a conference organised by the Marine Conservation Society, 22 May 1991. MCS, Ross-on-Wye, UK, pp. 19-22.

Murray S.N., Ambrose R.F., Bohnsack J.A., Botsford L.W., Carr M.H., Davis G.E., Dayton P.K., Gotshall D., Gunderson D.R., Hixon M.A., Lubchenco J., Mangel M., MacCall A., McArdle D.A., Ogden J.C., Roughgarden J., Starr R.M., Tegner M.J. and Yoklavich M.M. (1999) No-take reserve networks: sustaining fishery populations and marine ecosystems. Fisheries 24(11), 11-25.

Musick J.A., Berkeley S.A. and Warren M.L. (2000) Protection of marine fish stocks at risk of extinction. Fisheries 25(3), 6-8.

NCEAS (2001) Scientific consensus statement on marine reserves and marine protected areas, National Center for Ecological Analysis and Synthesis, University of California - Santa Barbara. Journal of International Wildlife Law and Policy 4(1), 87-90.

NRC (National Research Council) (2001) Marine protected areas: tools for sustaining ocean ecosystems. National Academy Press, Washington, DC.

Nichols K. (1999) Coming to terms with "integrated coastal management": problems of meaning and method in a new arena of resource regulation. Prof. Geogr. 51(3), 388-399.

Nielsen J.R. and Vedsmand T. (1999) User participation and institutional change in fisheries management: a viable alternative to the failures of 'top-down' driven control? Ocean Coast. Manage. 42, 19-37.

Norse E.A. (ed.) (1993) Global marine biological diversity: a strategy for building conservation into decision making. Washington DC: Island Press, pp. 37-86.

Nowlis J.S. and Roberts C.M. (1999) Fisheries benefits and optimum design of marine reserves. Fish. B.-NOAA 97(3), 604-616.

Ormond R., Bradbury R., Bainbridge S., Fabricius K., Keesing J., de Vantier L., Medlay P. and Steven A. (1990) Test of a model of regulation of crown-of-thorns starfish by fish predators, In Bradbury R.H. (ed.) Acanthaster and the coral reef: A theoretical perspective. Springer-Verlag, Berlin, pp. 189-207. 
Paulson D.D. (1998) Collaborative management of public rangeland in Wyoming: lessons in co-management. Prof. Geogr. 50(3), 301-315.

Pearsall S.H. (1984) In absentia benefits of nature preserves: a review. Environ. Conserv. 11(1), 3-10.

Peterson C.H. and Lubchenco J. (1997) Marine ecosystem services. In Daily G. (ed.) Nature's services: societal dependence on natural ecosystems. Island Press, Washington, DC, pp. 177-194.

Pitcher T.J. (2001) Fisheries managed to rebuild ecosystems? Reconstructing the past to salvage the future. Ecol. Appl. 11(2), 601-617.

Polunin N.V.C. (1984) Do traditional marine "reserves" conserve? A view of Indonesian and New Guinean evidence. Senri Ethnological Studies 17, pp. 267-283.

Powles H., Bradford M.J., Bradford R.G., Doubleday W.G., Innes S. and Levings C.D. (2000) Assessing and protecting endangered marine species. ICES J. Mar. Sci. 57(3), 669-676.

Price A.R.G. and Humphrey S.L. (Eds) (1993) Application of the Biosphere Reserve concept to coastal marine areas. A Marine Conservation and Development Report. IUCN, Gland, Switzerland.

Prideaux M., Emmet J. and Horstman M. (1998) Sustainable use or multiple abuse? Habitat Australia 26(2), 1320.

Ravetz J.R. (1999) What is post-normal science? Futures 31(7), 647-653.

Ray G.C. (1976) Critical marine habitats. In IUCN (1976), pp. 15-59.

Ray G.C. (1996) Coastal-marine discontinuities and synergisms: implications for biodiversity and conservation. Biodivers. Conserv. 5(9), 1095-1108.

Ray G.C. (1999) Coastal-marine protected areas: agonies of choice. Aquatic Conserv: Mar. Freshw. Ecosyst. 9(6), 607-614.

Ray G.C. and McCormick-Ray M.G. (1994) Critical habitats and representative systems in marine environments: concepts and procedures. In Agardy (ed.) (1994), pp. 23-40.

Reaser J.K., Pomerance R. and Thomas P.O. (2000) Coral bleaching and global climate change: scientific findings and policy recommendations. Conserv. Biol. 14(5), 1500-1511.

Roberts C.M. (1997) Connectivity and management of Caribbean coral reefs. Science 278, 1454-1457.

Roberts C.M. (1998) Sources, sinks and the design of marine reserve networks. Fisheries 23(7), 16-19.

Roberts C.M. (2000) Selecting marine reserve locations: optimality versus opportunism. B. Mar. Sci. 66(3), 581592.

Roberts C.M. and Hawkins J.P. (1999) Extinction risk in the sea. Trends Ecol. Evol. 14(6), 241-246.

Roberts C.M. and Hawkins J.P. (2000) Fully-protected marine reserves: a guide. WWF Endangered Seas Campaign, Washington, DC.

Roberts C.M., Bohnsack J.A., Gell F., Hawkins J.P. and Goodridge R. (2001) Effects of marine reserves on adjacent fisheries. Science 294(5548), 1920-1923.

Salm R.V. and Clark J.R. (1984) Marine and coastal protected areas: a guide for planners and managers. IUCN, Gland, Switzerland. 
Salm R.V., Clark J.R. and Siirila E. (2000) Marine and coastal protected areas: a guide for planners and managers ( $3^{\text {rd }}$ Edition). IUCN, Washington DC.

Salm R.V., Smith S.E. and Llewellyn G. (2001) Mitigating the impact of coral bleaching through marine protected area design. In Schuttenberg H.Z. (ed.) Coral Bleaching: Causes, Consequences and Response. Selected papers presented at the $9^{\text {th }}$ International Coral Reef Symposium on "Coral Bleaching: Assessing and Linking Ecological and Socio-economic Impacts, Future Trends and Mitigation Planning. Coastal Management." Report \#2230, Coastal Resources Center, University of Rhode Island, pp. 81-88.

Sanford E. (1999) Regulation of keystone predation by small changes in ocean temperature. Science 283(5410), 2095-2097.

Sapp J.(1999) What is natural? Coral reef crisis. Oxford University Press, New York.

Seymour R.M. and Bradbury R.H. (1999) Lengthening reef recovery times from crown-of-thorns outbreaks signal systemic degradation of the Great Barrier Reef. Mar. Ecol. Prog. Ser. 176, 1-10.

Sharpe B. (1998) First the forest: conservation, community and participation in south-west Cameroon. Africa 68(1), 25-45.

Silva M.E. and Desilvestre I. (1986) Marine coastal protected areas in Latin America: a preliminary assessment. Coast. Zone Manage. J. 14 (4), 311-347.

Spalding M.D., Ravilious C. and Green E.P. (2001) World Atlas of Coral Reefs. University of California Press.

Sumaila U.R., Guénette S., Alder J. and Chuenpagdee R. (2000) Addressing ecosystem effects of fishing using marine protected areas. ICES J. Mar. Sci. 57(3), 752-760.

Sutherland W.J. and Hill D.A (eds) (1995) Managing habitats for conservation. University Press, Cambridge, UK.

Tarnas D.A. (1988) The US National Marine Sanctuary Program: an analysis of the Program's implementation and current issues. Coast. Manag. 16, 275-303.

Timmermann A., Oberhuber J., Bacher A., Esch M., Latif M. and Roeckner E. (1999) Increased El Niño frequency in a climate model forced by future greenhouse warming. Nature 398(6729), 694-697.

Tisdell C. and Broadus J.M. (1989) Policy issues related to the establishment and management of marine reserves. Coast. Manag. 17, 37-53.

Tsing A.L., Brosius J.P. and Zerner C. (1999) Assessing community-based natural resource management. Ambio 28(2), 197-198.

UNCED (1992) Convention on Biological Diversity, Article 8.

UNEP (United Nations Environment Programme) (1995) Global biodiversity assessment. Cambridge University Press.

Vanderklift M.A. and Ward T.J. (2000) Using biological survey data when selecting marine protected areas: an operational framework and associated risks. Pacific Conservation Biology 6, 152-161.

Vitousek P.M., Mooney H.A., Lubchenco J. and Melillo J.M. (1997) Human domination of earth's ecosystems. Science 277, 494-499.

Wilkinson C., Lindén O., Cesar H., Hodgson G., Rubens J. and Strong A.E (1999) Ecological and socioeconomic impacts of 1998 coral mortality in the Indian Ocean: an ENSO impact and a warning of future change? Ambio 28(2), 188-196. 
Zacharias M.A., Howes D.E., Harper J.R. and Wainwright P. (1998) The British Columbia marine ecosystem classification: rationale, development and verification. Coast. Manag. 26, 105-124. 
Table 1. Distribution of MPAs amongst the 18 biogeographic regions and priorities for new or improved MPAs (after Kelleher et al., 1995)

\begin{tabular}{|c|c|c|c|c|c|c|}
\hline $\begin{array}{c}\text { Marine } \\
\text { Biogeographic } \\
\text { Region }\end{array}$ & $\begin{array}{c}\text { Total } \\
\text { Number } \\
\text { of MPAs }\end{array}$ & $\begin{array}{c}\text { Percentage of } \\
\text { total number } \\
\text { of MPAs }\end{array}$ & $\begin{array}{c}\text { Priority } \\
\text { new } \\
\text { MPAs }\end{array}$ & $\begin{array}{c}\text { Priority } \\
\text { improved } \\
\text { MPAs }\end{array}$ & $\begin{array}{r}\text { Number/per } \\
\text { Biogeographic } \\
\text { Region with }\end{array}$ & \\
\hline Antarctic & 17 & $1.3 \%$ & \multicolumn{4}{|c|}{ No agreed biogeographic zone classification } \\
\hline Arctic & 16 & $1.2 \%$ & 2 & 4 & 1 & $20 \%$ \\
\hline Mediterranean & 53 & $4.0 \%$ & 4 & 0 & 2 & $20 \%$ \\
\hline Northwest Atlantic & 89 & $6.8 \%$ & 4 & 0 & 0 & $0 \%$ \\
\hline Northeast Atlantic & 41 & $3.1 \%$ & 5 & 18 & 1 & $17 \%$ \\
\hline Baltic & 43 & $3.2 \%$ & 5 & 5 & 1 & $11 \%$ \\
\hline Wider Caribbean & 104 & $7.9 \%$ & 3 & 3 & 1 & $17 \%$ \\
\hline West Africa & 42 & $3.2 \%$ & 9 & 3 & 1 & $20 \%$ \\
\hline South Atlantic & 19 & $1.4 \%$ & 3 & 5 & 1 & $20 \%$ \\
\hline C. Indian Ocean & 15 & $1.1 \%$ & 5 & 4 & 2 & $33 \%$ \\
\hline Arabian Seas & 19 & $1.4 \%$ & 11 & 0 & 5 & $38 \%$ \\
\hline East Africa & 54 & $4.1 \%$ & 3 & 6 & 2 & $40 \%$ \\
\hline East Asian Seas & 92 & $7.0 \%$ & 1 & 9 & 0 & $0 \%$ \\
\hline South Pacific & 66 & $5.0 \%$ & \multicolumn{2}{|c|}{ Insufficient information } & 8 & $40 \%$ \\
\hline Northeast Pacific & 168 & $12.8 \%$ & 3 & 3 & 1 & $11 \%$ \\
\hline Northwest Pacific & 190 & $14.5 \%$ & 6 & 0 & 1 & $12 \%$ \\
\hline Southeast Pacific & 18 & $1.3 \%$ & 2 & 6 & 3 & $50 \%$ \\
\hline $\begin{array}{l}\text { Australia/New } \\
\text { Zealand }\end{array}$ & 260 & $19.9 \%$ & 16 & 7 & 2 & $11 \%$ \\
\hline Total & 1,306 & $100.0 \%$ & 82 & 73 & 32 & $21 \%$ \\
\hline
\end{tabular}

Table 2. Management effectiveness of MPAs (after Kelleher et al., 1995)

\begin{tabular}{lcr}
\hline \multicolumn{1}{c}{ Management Level } & Number/percentage of MPAs \\
\hline $\begin{array}{l}\text { High: generally achieving management } \\
\text { objectives }\end{array}$ & 117 & $31 \%$ \\
\hline $\begin{array}{l}\text { Moderate: partially achieving } \\
\text { management objectives }\end{array}$ & 155 & $40 \%$ \\
\hline $\begin{array}{l}\text { Low: generally failing to meet } \\
\text { management objectives }\end{array}$ & 111 & $29 \%$ \\
\hline $\begin{array}{l}\text { Sub-total: MPAs for which sufficient } \\
\text { management information was available }\end{array}$ & 383 & $\begin{array}{r}\text { (representing } \\
\text { total) }\end{array}$ \\
\hline $\begin{array}{l}\text { Unknown: insufficient management } \\
\text { information available }\end{array}$ & 923 & $71 \%$ \\
\hline \begin{tabular}{l} 
Total \\
\hline
\end{tabular} & 1,306 & $100 \%$ \\
\hline
\end{tabular}


Figure 1. Different stances concerning the selection, design and management of MPAs

Top-down: based primarily on strategic scientific priorities

$\begin{array}{ccccc}\begin{array}{c}\text { Emphasis on } \\ \text { Enforcement }\end{array} & \begin{array}{c}\text { Executive cross- } \\ \text { sectoral authority }\end{array} & \begin{array}{c}\text { Education to } \\ \text { justify restrictions } \\ \text { and promote } \\ \text { compliance }\end{array} & \begin{array}{c}\text { Reliance on } \\ \text { comprehensive } \\ \text { scientific information }\end{array} & \begin{array}{c}\text { Little scope for } \\ \text { compromise }\end{array} \\ \uparrow & \downarrow & \downarrow & \downarrow & \uparrow \\ \begin{array}{c}\text { Emphasis on } \\ \text { stakeholder } \\ \text { participation and } \\ \text { cooperation }\end{array} & \begin{array}{c}\text { Community-based } \\ \text { partnership }\end{array} & \begin{array}{c}\text { Education to } \\ \text { promote support } \\ \text { and participation }\end{array} & \begin{array}{c}\text { Science used for } \\ \text { guidance } \\ \text { where appropriate and } \\ \text { available }\end{array} & \begin{array}{c}\text { Greater scope for } \\ \text { compromise }\end{array}\end{array}$

Bottom-up: based primarily on socio-economic priorities guided by science

Figure 2. Differences between top-down and bottom-up infrastructures

\begin{tabular}{|c|c|c|c|}
\hline Sectoral law & $\begin{array}{l}\text { International-national- } \\
\text { regional policy }\end{array}$ & $\begin{array}{c}\text { Statutory objectives and } \\
\text { imperatives }\end{array}$ & $\begin{array}{c}\text { Institutional "ways of doing } \\
\text { business" }\end{array}$ \\
\hline$\downarrow$ & $\downarrow$ & $\downarrow$ & $\downarrow$ \\
\hline$\uparrow$ & $\uparrow$ & $\uparrow$ & $\uparrow$ \\
\hline Customs & Largely local view & $\begin{array}{c}\text { Collective \& } \\
\text { selfish objectives }\end{array}$ & $\begin{array}{l}\text { Informal communications and } \\
\text { "ways of working" }\end{array}$ \\
\hline
\end{tabular}

